\title{
Evaluation of the Role of Inventory Management in Logistics Chain of an Organisation
}

\author{
Oluwaseyi Joseph Afolabi ${ }^{1 *}$, Morakinyo Kehinde Onifade ${ }^{1}$ and Odeyinka Olumide F. ${ }^{1}$ \\ ${ }^{1}$ Bells University of Technology, Department of Management Technology, Ota, Nigeria; Email: \\ afolabiseyo@yahoo.com,morakinyo.onifade@yahoo.com,olumideodeyinka@gmail.com
}

*Corresponding Author: Oluwaseyi Joseph Afolabi

\begin{abstract}
The operation of inventory management determines the efficiency of storage of products. The progress in techniques and management principles improves the moving load, delivery speed, service quality, operation costs, the usage of facilities and energy saving. Inventory management takes a crucial part in the manipulation of logistics. Reviewing the current condition, a strong system needs a clear frame of logistics and a proper inventory implements and techniques to link the producing procedures. The objective of the paper is to define the role of inventory management in logistics for the reference of further improvement. The research was undertaken to assist logistics managers, researchers and inventory planners to define and comprehend the basic views of logistics and its various applications and the relationships between logistics and inventory.
\end{abstract}

Keywords: Logistics chain, stock, performance, organization, techniques

\section{Introduction}

Inventory management is one of the most important business processes during the operation of a manufacturing or production company as it relates to purchases, sales and logistic activities. It concerned with the control of stocks throughout the whole supply chain. Inventory control sits at the data level where the day-to-day business is organized. Activities here are data driven and are primarily concerned with short-term planning and recording of events. Inventory control is concerned with maintaining the correct level of stock and recording its movement.

According to [1], inventory management refers to all the activities involved in developing and managing the inventory levels of raw materials, semi-finished materials (work-in-progress) and finished good so that adequate supplies are available and the costs of over or under stocks are low. Inventories are essential for keeping the production wheels moving, keep the market going and the 
distribution system intact. They serve as lubrication and spring for the production and distribution systems of organizations.

Inventory is essential to organization for production activities, maintenance of plant and machinery as well as other operational requirements. This results in tying up of money or capital which could have been used more productively. The management of an organization becomes very concerned if inventory stocks are high. This therefore calls for its close scrutiny by management. Management is very critical about any shortage of inventory items required for production. Any increase in the redundancy of machinery or operations due to shortages of inventory may lead to production loss and its associated costs.

In a manufacturing system, even for a very complicate and flexible process of different products, the physical arrangement and capabilities of machines usually determines how production control should operate. The machines are not specified only for one task and the different tools need to be set up every time when the work changes [2].

Managing supply chain cost is the most important aspect of an organization; to achieve this, an organization has to employ qualified professional who understand inventory management techniques.

\section{Overview of Logistics}

[3] defined that logistics is 'part of the supply chain process that plans, implements, and controls the efficient, effective forward and reverse flow and storage of goods, services, and related information between the point of origin and the point of consumption in order to meet customers' requirements'. Logistics describes the entire process of materials and products moving into, through, and out of firm. Inbound logistics covers the movement of material received from suppliers. Materials management describes the movement of materials and components within a firm. Physical distribution refers to the movement of goods outward from the end of the assembly line to the customer.

The commonality of the recent definitions is that logistics is a process of moving and handling goods and materials, from the beginning to the end of the production, sale process and waste disposal, to satisfy customers and add business competitiveness. It is 'the process of anticipating customer needs and wants; acquiring the capital, materials, people, technologies, and information necessary to meet those needs and wants; optimising the goods- or service-producing network to fulfill customer requests; and utilizing the network to fulfill customer requests in a timely way' [4]. Simply to say, 'logistics is customer-oriented operation management'. 


\section{Conceptual Framework}

The essence of inventory management is to augment business operations so as to ensure effective flow of goods, products, and services [5]. In this context, 'inventory' is the aggregate list of items; a quantity of goods in stock or stock of the product which an organization is producing for sale and the components that make the sale. 'Stock' consists of a wide range of goods or materials - stationery, office equipment, plant, machinery, consumables, etc. available for use or sale.

\subsection{Types of Inventory}

Inventory can be classified into three types which include;

i. Raw material inventory: This includes all items purchased by an organization for processing. For instance, Flour, yeast, eggs etc. are all part of raw materials inventory of a confectionary organization.

ii. Work-In-Progress Inventory: This is an intermediate stage of raw material inventory that is yet to be finished by the plant to enter into another stage of processing. These are materials that have been partly processed but are yet uncompleted.

iii. Finished Goods Inventory: This is the stock of finished goods. These could be stock of goods awaiting shipment or in the warehouse, the level of finished goods stock is a matter of co-ordination between the production and sales departments of the organization.

\subsection{Storage and Warehousing}

Warehousing is one of the main spheres of logistics. The very broad meaning of it is storage of finished goods or materials (raw and components) for manufacturing, agricultural or commercial purposes. In fact, warehousing contains numerous functions, like acceptance of products (loading, unloading), inspection, and "proper storage". It is the whole system (warehouse management system) that includes warehouse infrastructure, tracking systems and communication "between product stations". One of the most sustainable trends in storage solutions is the "Just in Time technique". It means product delivery directly from supplier to producer without warehousing. But this system has quite limited application as the distances between intermediaries are growing with the globalization process of the world economy. Modern logistics cannot survive without warehousing service, but various sustainable modifications of warehousing infrastructure can be introduced. 


\section{Organizational Logistics Chain Performance}

Inventory management techniques and organizational supply chain performance need to be looked into keenly to avoid organizations use of huge chunk of its budget on holding inventory. It should ensure that customers are satisfied with its services by providing feedback and ensuring the concept of time, place and costs are maintained at optimal levels. Hence, the total cost model needs to be balanced by ensuring purchase costs, ordering costs and holding costs are minimal so that the firm can reap good profits or it maintains its budgetary allocation [6].

Managing supply chain cost is the far most important aspect of an organization and to achieve this, an organization has to bring on board qualified professional who understand the technical background of inventory management. Supply chain management need to be highly enhanced in the modern world because firms are engaging each other with high level of competition. Efficiency is required and to achieve this, highly qualified staff should be hired and utilize the latest technology such as the use of Enterprise Resource Planning (ERP) and Material Requirement Planning (MRP). By so doing, organization performance will be achieved when the staff fully understands how to apply inventory management techniques which will necessitate demand planning, forecasting and location.

The main objective of inventory management is to minimize the total cost of relevant costs to ensure profitable operations as well as maximize the customer service level. To be specific, the objective of inventory control include: to ensure adequate supply of products to customer and avoid shortages as far as possible; to make sure that the financial investment in inventories is minimum (i.e., to see that the working capital is blocked to the minimum possible extent); efficient purchasing, storing, consumption and accounting for materials is an important objective; to maintain timely record of inventories of all the items and to maintain the stock within the desired limits; to ensure timely action for replenishment; to provide a reserve stock for variations in lead times of delivery of materials; to provide a scientific base for both short-term and long-term planning of materials.

\section{Inventory Management Techniques}

Inventory management techniques are extremely important for business operations because their success and cost reduction of the firm's expenditure necessitate improved supply chain performance and knowledge to the employees. These techniques are critical and knowledge in them is highly desirable thus, managers and procurement staff need to be able to apply the techniques for the benefit of the organization. 


\subsection{Economic Order Quantity}

The Economic Order Quantity (EOQ) model of inventory management is used to mark the optimum size of delivery and to choose the cheapest deliverer which guarantees minimization of total costs of investments in inventories. EOQ model is a technique that determines the optimal amount of inventory to order each time the inventory of that item is depleted [7]. The Economic Order Quantity (EOQ) model considers the trade-off between ordering cost and storage cost in choosing the quantity to use in replenishing item inventories. A larger order-quantity reduces ordering frequency and hence ordering cost, but requires holding a larger average inventory, which increases holding costs. On the other hand, a smaller order-quantity reduces average inventory, but requires more frequent ordering and higher ordering costs.

The EOQ model makes the following assumptions:

- Demand is constant and known with certainty.

- Depletion of stock is linear and constant.

- No discount is allowed for quantity purchases.

- The time interval between placing an order and receiving delivery is constant.

\subsection{Vendor-Managed Inventory (VMI)}

Under the VMI technique, significant gains can be made through transparent collaboration with credible vendors of critical inventories, especially in large-sized production management. VMI enables the vendor in a vendor/customer relationship to plan, monitor, and control inventory for their customers, with the vendor taking responsibility for managing the inventory within specific levels previously agreed upon, while the customer concentrates on improving demand accuracy. The customer-organization relinquishes the order-making responsibilities in exchange for timely inventory replenishment that ultimately works towards increasing overall capacity planning and institutional efficiency. Mathematical models can be developed such that the total cost of the inventory management system (vendor's and buyer / customer costs) is minimized.

\subsection{Just-In-Time}

As the name implies, JIT is a model that attempts to replenish inventory for organizations just when the inventory is required. It will be the preferred method for very expensive inventory items, that is, items with relatively higher purchase price, holding costs or ordering cost, but low levels of demand. The model attempts to avoid excess inventory and its associated costs. As a result, organizations receive 
inventory only when the need for more stock is approaching. For JIT approach to succeed, a crucial requirement is to ensure timely delivery by the vendor. This is to avoid expensive and irreparable business downtimes occasioned by any delay in inventory delivery.

Just-in-time, as an evolving area in scheduling, aims to improve return on investment by reducing in-process inventory and associated carrying costs. As a production scheduling strategy, JIT is indicated in single and parallel machines environments while it is beginning to be considered in the flow shop machine environment [8].

\subsection{Activity Based Costing Analysis}

[9] agree that having inventory in your store has an added advantage for the organization since customers will be satisfied instantly leading to improved performance rating. With inventory in your warehouse, an organization has the advantage of timely delivery and stock out are not experienced. Thus, organizations need to ensure that they have adequate stock for their operations and distribution. One way they can achieve this is through the "Pareto Analysis" also known as Activity Based Costing $(\mathrm{ABC})$ analysis. The $\mathrm{ABC}$ system is a widely used classification technique to identify various items of inventory for purposes of inventory control.

On the basis of unit cost involved, the various items are classified into 3 categories:

- A, consisting of items with the large investment,

- $\mathrm{C}$, with relatively small investments but fairly large number of items and

- B, which stands mid-way between category A \& C.

Category A needs the most rigorous control, $\mathrm{C}$ requires minimum attention and $\mathrm{B}$ deserves less attention than A but more than $\mathrm{C}$.

Steps for implementation of $\mathrm{ABC}$ analysis are,

a) Classify the items of inventories determining the expected use in units and the price per unit for each item.

b) Determine the total value for each item by multiplying the expected units by its unit price.

c) Rank the items in accordance with the total value, giving first rank to the items with highest total value and so on.

d) Compute the ratio (percentages) of number of units of each item to total units of all items and the ratio of total value of each item to total value of all items.

e) Combine items on the basis of their relative value to form three categories A, B and C. 
Table 1 Activity Based Costing. Source: authors

\begin{tabular}{l|l|l|l}
\hline Particulars A item & A item & B item & C item \\
\hline Control & Tight & Moderate & Loose \\
Requirement & Exact Close & Exact Some & Estimated \\
Check & Regular & Some & Little/No \\
Expenditure & Industrial & Individual & Group/None \\
Posting & Low & Medium & \\
Safety Stock & High & & Rare \\
\hline
\end{tabular}

\subsection{Theoretical Proposition}

It is expected that the application of Economic Order Quantity, Marginal Analysis, Just-in-Time, Simulation, Order batching, Vendor Managed Inventory and ABC Analysis will improve company performance. As the organisation staff understands the strengths of having these techniques, then the unnecessary costs incurred will be avoided. Therefore, the techniques will improve performance in the following ways:

Table 2 Inventory Management Techniques. Source: [12]

\begin{tabular}{l|l|l}
\hline No & $\begin{array}{l}\text { Inventory Management } \\
\text { Techniques }\end{array}$ & $\begin{array}{l}\text { How Performance Improvement will be } \\
\text { achieved }\end{array}$ \\
\hline I & Economic Order Quantity & $\begin{array}{l}\text { Ability to know how much and when to } \\
\text { replenish inventory }\end{array}$ \\
\hline ii & Marginal Analysis & $\begin{array}{l}\text { Reduce loss for inventory that is perishable } \\
\text { within a short period of time by ensuring } \\
\text { they are ordered at the right time. }\end{array}$ \\
\hline iv & Simulation & $\begin{array}{l}\text { Ordering inventory when they are required } \\
\text { thus reducing storage/holding costs }\end{array}$ \\
\hline v & Order Batching & $\begin{array}{l}\text { Capability of laying out inventory } \\
\text { management plans for the organization }\end{array}$ \\
\hline vi & Vendor Managed Inventory & $\begin{array}{l}\text { Minimizing on unnecessary costs on } \\
\text { transport }\end{array}$ \\
\hline vii & ABC Analysis & $\begin{array}{l}\text { Improving on inventory management } \\
\text { systems by engaging outsourced suppliers to } \\
\text { management inventory monitoring and } \\
\text { replenishment. }\end{array}$ \\
\hline
\end{tabular}




\section{Review of Relevant Literature}

Inventory control is vitally important to almost every type of business, whether product or service oriented. Inventory control touches almost every facet of operations. A proper balance must be struck to maintain proper inventory with the minimum financial impact on the customer. Inventory control is the activities that maintain stock keeping items at desired levels. In manufacturing since the focus is on physical product, inventory control focus on material control. In order to have clear inventory management, a company should not only focus on logistic management but also on sales and purchase management. Inventory management and control is not only the responsibility of the accounting department and the warehouse, but also the responsibility of the entire organization.

[10] defines inventory management as a form of administration control that is particularly essential in all manufacturing, wholesale and retail organizations. The essence of inventory is, "to have the right goods, quality and quantity, at the right place and time". This process is needed as a part of supply chain network to protect production system against any kind of disturbance. Inventory control is the process of ensuring that the right quality of the relevant stock is available at the right time and in the right place.

Inventory management involves comparison between the costs associated with keeping inventory versus the benefits of holding inventory. Successful inventory management minimize inventory, lowers cost and improves profitability. An optimal inventory level can be based on consideration of the incremental profitability to the opportunity cost of carrying the higher inventory balances [11].

In this 21 st century, the internet and internet-based technologies are impacting business in several ways. The various internet and internet technologies that are used in inventory management include emails for accessing and contacting clients, website technologies designed for distributing, searching, and retrieving documents over the Internet. These new technologies are promising to save costs, to improve customer and supplier relationships, business processes and performance, and to open new business opportunities.

[12] opine that Inventory control problems have attracted researchers for many years. Fundamentally, the problem is one of matching supply and demand by efficiently coordinating the production and the distribution of goods. Recent developments in information technology have equipped managers with the means to obtain better and timely information regarding, for example, demand, lead times, available assets and capacity. Technology has also enabled customers to obtain vast amounts of information about a product, such as its physical attributes and availability. In today's increasingly competitive marketplace, consumers are constantly pressuring suppliers to simultaneously 
reduce costs and lead times and increase the quality of their products. Good inventory management is no longer a competitive advantage. It is an essential capability to survive in a global market.

An important aspect of good inventory management is effective use of information. Knowing how to use information effectively also enables a manager to decide what data to collect, buy and store, and what information technology to invest in. information has no value, if it is not used effectively. For example, an inventory manager can obtain order progress information through the use of a tracking technology. If this information is not used to improve replenishment decisions, then neither the information nor the technology used to obtain it has any value.

Inventory management involves a trade-off between the costs associated with keeping inventory versus the benefits of holding inventory. The benefit of an inventory is to assure that goods will be available as required. The primary costs of an inventory are the opportunity cost of the capital used to finance the inventory, ordering costs, and storage costs. Inventory management seeks to maximize the net benefit- the benefits minus costs - of the inventory [3].

Different inventory items vary in profitability as well as the amount of space they take up.

[13] recommends that the following actions take place within a company in the management of inventory:

- establish purchasing review criteria to review the inventory characteristics

- purchase only the amount of raw materials needed for a production run or a period of time

- Collaboration with vendors to improve the purchasing practice

- improve inventory control through application of effective inventory control systems

- encourage materials exchange within the company

- consider just-in-time manufacturing.

[12] found that effective inventory management was a capability necessary to lead in the global marketplace. He provides four fundamentals of effective inventory management:

- It requires managers to know how best to use available information.

- Managers need to quantify the value of information.

- They need to coordinate decentralized inventory operations.

- Effective inventory management requires decision tools that can be embraced by their users.

The new raw material inventory management policy is targeted at solving the existing problem of having excessive inventory by optimizing current raw material inventory level based on scientific models [14]. 
The importance of inventory management for small and medium-sized manufacturing companies proved [15] who analyzed its influence on economic performance. His study was aimed especially at machine tool industries sector in India which was an extremely inventory intensive. The results showed that inventory management had really some impact on labor productivity, capital productivity and returns to scale in respondent companies.

\section{Conclusion}

This paper covers broadly from logistics activities to inventory systems and attempts to determine the role of inventory in logistics systems through extensive review. The main contents of the research include a review of logistics development, the characters of various inventory operations in logistics activities, the applications of logistics in various fields, and its cooperation with inventory systems.

Inventory and logistics systems have interdependent relationships. Logistics management needs inventory management to perform its activities and meanwhile, a successful logistics system could help to improve warehouse environment and operational activities [16]. Inventory plays an important role in logistics system and its activities appear in various sections of logistics processes [17]. Without the linking of Inventory with other logistics activities, a powerful logistics strategy cannot bring its capacity into full play.

\section{References}

[1] Kotler, P. (2002). Social Marketing Improving the Quality of Life, 2nd edition. Prentice Hall, New Jersey Ltd., UK.

[2] Kumar, P. \& Anas, M. (2013). An ABC-Analysis for the Multiple- Products Inventory Management. International Journal of Research in Engineering \& Advanced Technology, 1(5). ISSN 2320-8791.

[3] Council of Logistics Management. (1991). Definition of Logistics, from http://www.cscmp.org/.

[4] Tilanus, B. (1997). Information Systems in Logistics and Transportation. Elsevier Science. 350 p. ISBN 978-0080430546.

[5] Chalotra, V. (2013). Inventory management and small firms' growth: An analytical study in supply chain. Vision, 17(3), 213-222. 
[6] Kavulya, J. (2004). University Libraries in Kenya A Study of Their Practices and Performance. Humboldt University in Berlin. Berlin: Unpublished MBA Project.

[7] Chambers, D. \& Lacey, N. (2011). Modern Corporate Finance, Sixth Edition, Michigan: Hayden McNeil Publishing.

[8] Adamu, M.O., Budlender, N. \& Idowu, G.A. (2014). A note on Just-in-Time scheduling on flow shop machines. Journal of the Nigerian Mathematical Society, 33, 321-331.

[9] Fellows, P. \& Rottger, A. (2005). Business Management for Small-Scale Agro-Processors. Agricultural Management, Marketing Management and Finance Service (AGSF). FAO of the United Nations, Agricultural Support Systems Division. Rome: Food and agricultural Organization of the United Nations. Jovanovich Inc.

[10] Nwandu. (2006). Principles of Management, Enugu: Allmark Publishing Ltd.

[11] Kontuš \& Kastav. (2014). Management of Inventory in a Company.

[12] Ozer, O. (2014). Inventory Management: Information, Coordination and Rationality. Management Science and Engineering Stanford University Stanford, CA 94305.

[13] McComas, C. (1995). Controlling Purchasing and Inventory to Reduce Waste, Pollution Prevention. Review, 5.

[14] Wang, X. (2010). Inventory Management in a Pharmaceutical Company: Minimizing Discard Practices, National University of Singapore, Singapore.

[15] Rajeev, N. (2010). Do Inventory Management Practices Affect Economic Performance? An Empirical Evaluation of the Machine Tool SMEs in Bangalore. International Journal of Innovation and Technology Management, 4(7), 312-320. ISSN 1750-9653.

[16] Sawaya Jr. \& Giauque. (2006). Production and Operations Management Orlando FL: Harcourt Brace.

[17] Tseng, Y., Taylor, M.A.P. \& Yue, W.L. (2005). The Role of Transportation in Logistics Chain. In Proceedings of the Eastern Asia Society for Transportation Studies, 2005, Vol. 5 (pp. 1657 1672). 